\title{
Automatic Estimation of Nitrogen content in Cotton (Gossypium Hirsutum L) Plant by using Image Processing Techniques: A Review
}

\author{
Asaram Pandurang Janwale \\ Professor, Dept. of Computer Science \\ Balbhim College Beed (MS) India \\ janwale26@gmail.com
}

\author{
Santosh S. Lomte, PhD \\ College of Engineering and Technology \\ Aurangabad (MS) India
}

\begin{abstract}
Cotton is an important crop in India. Yield depends on many factors like nutrients, water etc. Nitrogen plays important role to increase yield. It is an important to detect and manage Nitrogen deficiency in cotton crop. There are different methods for Nitrogen detection like color analysis using deferent color analysis model, remote sensing, and neural network etc. This paper reviews these different techniques used to detect Nitrogen deficiency in cotton plant and conclude Image processing techniques using color models is the best technique to detect deficiency in cotton plant easily, inexpensively and more accurately.
\end{abstract}

Keywords:- Nitrogen deficiency, Cotton plant, neural network, remote sensing, color models.

\section{INTRODUCTION}

India is one of the growing country in the world; one of the reason behind it is its ruler demand. India's ruler demand completely depends on the agriculture field. If there is good monsoon it results in good crop yield. But to fulfill the food requirement of large population, it is required to increase the crop yield. The productivity and the quality of the cultivated crops heavily depend on the natural factors like nutrients, water, etc. It needs to apply externally if natural resources not fulfill the crop requirements. It increases the productivity cost. Because of this, now a day it has been seen agriculture is not a profitable business, because of small difference between production costs and market price of crop. It has been found that cotton belt of India has more suicide cases of farmers. In some regions of India like Vidarbha and Marathwada, suicide cases of farmers have been increased. So it is necessary to decrease the production cost and give some more bucks in Farmer's hand. In agriculture some of the major expenditure is on seeds, fertilization and pesticides. Technology can help here to decrease the production cost by using new techniques in agriculture.

Cotton is important crop of India. India has the largest cotton growing area in the world with about 115 lakh hectares under cultivation accounting for one-fourth of the global cotton area. It contributes to 375 - lakh Bales of $170 \mathrm{kgs}$ and has emerged as the world's first largest cotton producer in 2013-14 [11]. Maharashtra is the important cotton growing state in India with 38.72 lacks hectors area and production of approximate 81 lack bales, about 3 million farmers is engaged in cotton cultivation in the state mostly in backward region of Marathwada and Vidarbha. Fertilization is the key factor and it fulfills the nutrient requirements of crop. It is important to identify the need and managing fertilization with the help of computer. Nitrogen, Potassium and Phosphorus are the three important nutrients required to plants.

\subsection{Role of Nitrogen in Cotton Plant:}

Nitrogen is one of the important nutrients required to crops. It is present in the chlorophyll of leaves and used to channelize the sun energy to carbohydrates, which provides energy to crop. It is also responsible for growth and yield. Nitrogen deficiency can affect photosynthesis process; it can reduce leaf size, number of fruiting nodes, yield, and fiber quality. This can also limit water and nutrient uptake and cause excessively early cutout.

Excess nitrogen can delay maturity, excessive growth, decrease boll retention, low fiber quality, increase pest problems and pollute ground and surface water. Thus it is needed to have automated techniques to find the Nitrogen concentration and detect deficiency. There are lots of techniques developed to identify $\mathrm{N}$ deficiencies present in cotton plant such as digital image processing, remote sensing, and neural network technique and so on. This article reviews techniques used for detecting $\mathrm{N}$ deficiencies in cotton plant.

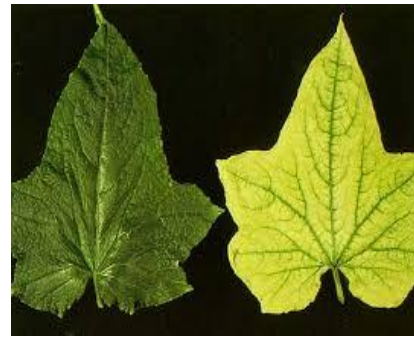

a.

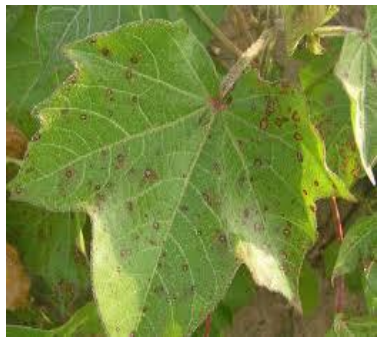

b.
Fig (a, b) showing Nitrogen deficiency.

There are different methods to estimate Nitrogen in plant leaves. Destructive methods includes chemical analysis are time consuming and expensive. Nondestructive method like SPAD 502 meter is commonly used handheld device, which gives less accurate estimates. So digital image processing is proving to be new technology with high accuracy and less time. There are lot methods devolved for estimation of Nitrogen, which is discussed below. 


\section{LITERATURE SURVEY}

Chlorophyll and Nitrogen are correlated to each other, so there are number of techniques which uses different color models, Artificial Neural techniques, Remote sensing etc. for estimation.

\subsection{Color Analysis}

This study [1] was used to develop a nondestructive method for monitoring cotton growth and $\mathrm{N}$ status using a digital camera. Digital images were taken of the cotton canopies between emergence and full bloom. The green and red values were extracted from the digital images and then used to calculate canopy cover. The values of canopy cover were closely correlated with the normalized difference vegetation index and the ratio vegetation index and were measured using a Green Seeker handheld sensor. The result indicated that the best relationship between canopy cover and aboveground total $\mathrm{N}$ content had a $R^{2}$ value of 0.926 and an RMSE value of $1.631 \mathrm{gm}-2$.

In this study [2] various features of image of leaf were extracted such as the shape of leaf, area of leaf, shape of holes present on the leaf, disease spots etc. These features extracted using different image processing techniques. The feature extraction was the key point of this work. These extracted features were used to determine the occurrence of the particular deficiency related to primary nutrients of cotton plant. He used Sony cyber shot 14MP camera to take photo of cotton leaves. Nitrogen deficiency detected by two preliminary steps, Histogram analysis and measurement of leaf area. The leaf with deficiency has reduced area compared to that of normal leaf, to test the performance of the deficiency detection system; leaves are selected from different plots and different varieties of cotton.

The objectives of this study[3] was to determine the relationships of ground-based canopy spectral reflectance, spectral index and color parameters obtained by using digital camera (Olympus C-5060) and imaging spectrometer (MSI200). Results shows that the models to retrieve canopy leaf nitrogen contents using DI $\left(\mathrm{R}_{580}, \mathrm{R}_{680}\right)$ and $\mathrm{G}-\mathrm{R}$ were most feasible with the maximum determination coefficients $\left(\mathrm{R}^{2}\right)$ and the minimum standard error (SE) for two visible sensors, respectively. In addition, b* (CIE 1976 L*a*b* color model) and H (HSI color model) used as color parameters. It was found that the spectral index was superior to color parameters for the same sensor, and MSI200 superior to digital camera. They found that difference indices DI $\left(\mathrm{R}_{580}\right.$, $\mathrm{R}_{680}$ ) and G-R were the good indicators of canopy leaf nitrogen content with the highest predictive precision $(0.8131$ and 0.7636, respectively) and accuracy (1.0149 and 0.9661) and the lowest RMSE (2.3313 and $2.7406 \mathrm{mg} \mathrm{g}^{-1}$, approximately $6.52 \%$ and $8.24 \%$ of the mean). Hence, canopy spectral parameters in visible region may provide an effective and feasible means of estimating canopy leaf nitrogen contents quantitatively in cotton field.

\subsection{Artificial Neural Network}

In this paper [4], a three-layer multilayer perception (MLP) artificial neural network (ANN) based prediction system was presented for predicting the leaf chlorophyll content from the cotton plant images. As the training of this prediction system relied heavily on how well those leaf green pixels were separated from background noises in cotton plant images, a global thresholding algorithm and an omnidirectional scan noise filtering coupled with the hue histogram statistic method were designed for leaf green pixel extraction. With the obtained leaf green pixels, the system training was carried out by applying a back propagation algorithm. The system was tested to predict the chlorophyll content from the cotton plant images. The results using the system were related with the obtained results by the destructive method. The average prediction relative error for the chlorophyll density $(\mu \mathrm{g} \mathrm{cm}-2)$ in the 17 testing images was $8.41 \%$.

In this study [5] the leaf analysis in a crop can present the need of a nutrient determined in the plant. The macronutrients deficiency in the cotton crop identified by specific type of colors variation by leaves images. This study investigates the image segmentation of the cotton leaves with deficiency of the phosphors. The segmentation is performed by difference of leaf pigmentation, according with the pattern related to macronutrient type in deficit and the cultivate. The image segmentation is made by an artificial neural network and the Otsu method. The results show satisfactory values with an optimized artificial neural network and better than the Otsu method. The results are presented by images and distinct parameters of quality analysis in the segmentation.

\subsection{Remote sensing}

This study [6] present results obtained with several new narrow-band hyper spectral obi dices calculated from the Airborne Visible and Near Infrared (AVNIR) hyper spectral sensor flown over a cotton (Gossypium hirsutum L.) field in California (USA) collected over an entire growing season at $1-\mathrm{m}$ spatial resolution. Within-field variability of yield monitor spatial data collected during harvest was correlated with hyper spectral indices related to crop growth and canopy structure, chlorophyll concentration, and water content. The time-series of indices calculated from the imagery were assessed to understand within-field yield variability in cotton at different growth stages. A $K$ means clustering method was used to perform field segmentation on hyper-spectral indices in classes of low, medium, and high yield, and confusion matrices were used to calculate the kappa $(\mathrm{k})$ coefficient and overall accuracy. Structural indices related to LAI [Renormalized Difference Vegetation Index (RDVI), Modified Triangular Vegetation Index (MTVI), and Optimized Soil-Adjusted Vegetation Index (OSAVI)] obtained the best relationships with yield and field segmentation at early growth stages. Hyper spectral indices related to crop physiological status [Modified Chlorophyll Absorption Index (MCARI) and Transformed Chlorophyll Absorption Index (TCARI)] were superior at later growth stages, close to harvest. From confusion matrices and class analyses, the overall accuracy (and kappa) of RDVI at early stages was $61 \%(\mathrm{k}=0.39)$, dropping to $39 \%(\mathrm{k}=0.08)$ before harvest. The MCARI chlorophyll index remained sensitive to within-field yield variability at late pre harvest stage, obtaining overall accuracy of $51 \%(\mathrm{k}=0.22)$.

In this study [7] ground-based sensing system was developed for determination of nitrogen $(\mathrm{N})$ status in cotton plants. The system consists of a multi-spectral optical sensor, an ultrasonic sensor, and a data-acquisition and processing unit. The optical sensor's light source provides modulated panchromatic illumination of a plant canopy with lightemitting diodes. The sensor measures plant reflectance at four spectral wavebands 400 to $500 \mathrm{~nm}, 520$ to $570 \mathrm{~nm}, 610$ to 710 $\mathrm{nm}$, and 750 to $1100 \mathrm{~nm}$. The ultrasonic sensor was used to determine plant height. The data-acquisition and processing unit was based on a single-board computer that collects data from the multi-spectral optical sensor and the ultrasonic sensor, and spatial information from a Global Positioning 
System receiver. Field tests of the system over two years involved measuring spectral reflectance and plant height simultaneously in real time in situ. An artificial neural network was developed to predict $\mathrm{N}$ status in cotton plants based on data from the sensing system. The network was trained with actual leaf $\mathrm{N}$ concentration data that corresponded to sensor spectral data and plant height. Results showed that the spectral information and plant height measured by the sensing system had significant correlation with leaf $\mathrm{N}$ concentration of the cotton plants. Trained neural networks were able to predict $\mathrm{N}$ status of the cotton plants at $90 \%$ accuracy when $\mathrm{N}$ status was divided into two categories: deficiency and non-deficiency.

\subsection{Canopy Reflectance}

In this study [8] ground-based hyper spectral data and concurrent TLCC parameters of samples were acquired. The results showed that the newly combined spectral indices, the ratio of the structure insensitive pigment index to the ratio vegetation index III (SIPI/RVI III), the ratio of the plant pigment ratio to the normalized difference vegetation index (PPR/NDVI), and the modified MERIS terrestrial chlorophyll index (MMTCI)] were more sensitive to chlorophyll and more resistant to LAI than the PPR, SIPI, and MERIS terrestrial chlorophyll index alone. In this study, DCNI I proved to be the best spectral index for estimating chlorophyll content, with determination coefficients (R2) and root mean square error (RMSE) values of 0.80 and $8.31 \mu \mathrm{g} \cdot \mathrm{cm}-2$, respectively. PPR/NDVI was also strongly correlated with chlorophyll content, with corresponding R2 and RMSE values of 0.79 and $9.45 \mu \mathrm{g} \mathrm{cm}-2$, respectively. This study concluded that DCNI I and PPR/NDVI, in association with indices related to nitrogen, have good potential for assessing nitrogen content.

In this study [9] some vegetation indices for estimating leaf EWT and EWT canopy were investigated using simulations and field measurements. Leaf and canopy spectral reflectance as well as leaf EWT and EWT canopy were measured in cotton during the growing seasons of 2010 and 2011. The PROSPECT-5 model was coupled with the SAILH model to explore the performance of water-related vegetation indices for leaf EWT and EWT canopy estimation. The vegetation indices evaluated were published formulations and new simple ratio vegetation indices formulated with wavebands at $1060 \mathrm{~nm}$ and $1640 \mathrm{~nm}$. The sensitivities of these indices to leaf internal structural $\mathrm{N}$ and LAI effects were assessed. Simulation results in dictated that all of the water-related vegetation indices were insensitive to leaf internal structural $\mathrm{N}$, with the highest coefficient of determination $\mathrm{R} 2<0.15$ and the proposed index SR1640 (R1060/R1640) and published index SR2 (R1070/R1340) showed the lowest relationships $(\mathrm{R} 2<0.35)$ with LAI of all the vegetation indices. Furthermore, coefficients of determination between simulated leaf EWT as well as EWT canopy and vegetation indices tested revealed that the new simple-ratio vegetation indices proposed in this study(SR1060: R1640/R1060and SR1640) were found to be significantly related with leaf EWT (R2> 0.9; P < 0.001) and EWT canopy (R2> 0.8; P < 0.001). Results obtained with field measurements were in agreement with simulation results, with the coefficient of determination $\mathrm{R} 2=$ $0.5(\mathrm{P}<0.001)$ for leaf EWT and $\mathrm{R} 2=0.57(\mathrm{P}<0.001)$ for EWT canopy by the new simple ratio indices. This study provides a new candidate for leaf EWT and EWT canopy estimation using hyper spectral vegetation indices.
From above studies here we can arrange this information in table form, which gives advantages and disadvantages of each method along with main principal.

Table 1 showing advantage and disadvantage of each method

\begin{tabular}{|c|c|c|c|}
\hline Technique & Principle & Advantages & Disadvantages \\
\hline $\begin{array}{l}\text { Color } \\
\text { Analysis }\end{array}$ & $\begin{array}{l}\text { RGB, HIS } \\
\text { and other } \\
\text { color } \\
\text { models. }\end{array}$ & $\begin{array}{l}\text { Less } \\
\text { Expensive, } \\
\text { higher- } \\
\text { efficiency, } \\
\text { Higher } \\
\text { profit in } \\
\text { estimating } \\
\text { the content } \\
\text { of nitrogen }\end{array}$ & $\begin{array}{l}\text { Covers less } \\
\text { sampling area. } \\
\text { Illumination in } \\
\text { Images. }\end{array}$ \\
\hline $\begin{array}{l}\text { Artificial } \\
\text { Neural } \\
\text { Network }\end{array}$ & $\begin{array}{l}\text { simple } \\
\text { processing } \\
\text { neuron like } \\
\text { processing } \\
\text { elements }\end{array}$ & $\begin{array}{l}\text { Highly non- } \\
\text { linear } \\
\text { modeling, } \\
\text { Easy to use } \\
\text { and } \\
\text { understand }\end{array}$ & $\begin{array}{l}\text { cannot deal } \\
\text { with } \\
\text { uncertainties }\end{array}$ \\
\hline $\begin{array}{l}\text { Remote } \\
\text { sensing }\end{array}$ & $\begin{array}{l}\text { Satellite } \\
\text { from orbit } \\
\text { used to take } \\
\text { images. }\end{array}$ & $\begin{array}{l}\text { Cover large } \\
\text { sampling } \\
\text { area, } \\
\text { Data } \\
\text { acquisition } \\
\text { at diff } \\
\text { scales and } \\
\text { resolution. }\end{array}$ & $\begin{array}{l}\text { Complex, } \\
\text { Expensive }\end{array}$ \\
\hline $\begin{array}{l}\text { Canopy } \\
\text { Reflectance }\end{array}$ & $\begin{array}{l}\text { Wide range } \\
\text { of } \\
\text { wavelengths }\end{array}$ & $\begin{array}{l}\text { Accurate } \\
\text { Non- } \\
\text { destructive } \\
\text { High } \\
\text { resolution } \\
\text { Portable }\end{array}$ & $\begin{array}{l}\text { Complex } \\
\text { Expensive } \\
\text { Required } \\
\text { training }\end{array}$ \\
\hline
\end{tabular}

\section{CONCLUSION}

An efficient, accurate and inexpensive method for detection of Nitrogen in cotton plant is important for better crop management. Technology can improve performance and accuracy of crop management and profitability of farmers. With proper management of Nitrogen we can supply proper amount of nitrogen to crop and also decrease its pollution to soil and water. In this paper we studied different methods for estimation of Nitrogen. Each method has its own advantages and disadvantages but we should have a method which is more accurate, inexpensive and easy to do its operations.

From table we can compare these methods on their advantages and disadvantages. From this study I can conclude that, as we have new cameras in market with high resolution and with less illumination, and easily available; so image processing method using color models can be more accurate and reliable and inexpensive. This problem can be solved in future by using high resolution cameras and will be used to give better results. 


\section{REFERENCES}

[1] Biao Jia et al. "Use of a Digital Camera to Monitor the Growth and Nitrogen Status of Cotton" Scientific World Journal Volume 2014, Article ID 602647.

[2] Mr. Swapnil S. Ayane et al. "Identification Of Nitrogen Deficiency In Cotton Plant By Using Image", IJPRET, 2013; Volume 1(8): 112-118.

[3] WANG Fang-Yong et al "Estimation of Canopy Leaf Nitrogen Status Using Imaging Spectrometer and Digital Camera in Cotton", Acta Agronomica Sinica 06/2011; 37(6):1039-1048. DOI: 10.3724/SP.J.1006.2011.01039

[4] Xing-mei SUO,"Artificial Neural Network to Predict Leaf Population Chlorophyll Content from Cotton Plant Images" Agricultural Sciences in China, Volume 9, Issue 1, January 2010, Pages 38-45, doi:10.1016/S16712927(09)60065-1.

[5] Maicon A. Sartin, Et Al. "Image Segmentation with Artificial Neural Network for Nutrient Deficiency in Cotton Crop" Journal of Computer Science 10 (6): 10841093, 2014, ISSN: 1549-3636, 2014 Science Publications doi:10.3844/jcssp.2014.1084.1093 Published Online 10 (6) 2014
[6] P. J. Zarco-Tejada et al "Temporal and Spatial Relationships between Within-Field Yield Variability in Cotton and High-Spatial Hyper spectral Remote Sensing Imagery" AGRONOMY JOURNAL, VOL. 97, MAY-JUNE 2005

[7] R. Sui, J. A. Thomasson "Ground-Based Sensing System for Cotton Nitrogen Status Determination", Vol. 49(6): 1983-1991_2006 American Society of Agricultural and Biological Engineers ISSN 0001-2351 1983.

[8] Xiuliang Jin et al. "Newly Combined Spectral Indices to Improve Estimation of Total Leaf Chlorophyll Content in Cotton",1939-1404 @ 2014 IEEE.

[9] Qiuxiang Yi et al. "Leaf and canopy water content estimation in cotton using hyper spectral indices and radiative transfer models", Elsevier International Journal of Applied Earth Observation and Geoinformation 33 (2014) 67-75

[10] Janwale Asaram Pandurng et al. Digital Image Processing Applications in Agriculture: A Survey

[11] ICAR-Central Institute for Cotton Research. http://www.cicr.org.in/ResearchNotes.html 